\title{
Choosing Wisely concept has universal appeal
}

I $\mathrm{t}$ began in the United States in 2012. Canada joined in 2014. It has since spread to Japan, Brazil, France, Germany, Israel, Australia and many other countries. The concept behind the Choosing Wisely campaign - that more health care isn't always better health care - appears to have universal appeal. And that's a rare thing on the international health care scene.

"It transcends all these different health care systems and different payment schemes because it resonates with doctors about the core essence of what it is to work with patients, and that is the same in every country," says Dr. Wendy Levinson, chair of Choosing Wisely Canada and a professor of medicine at the University of Toronto. "That is the amazing part of this story. Give me another example where there has been so much interest across countries in anything about changing health care systems."

If there were international discussions about how best to fund health care, for example, there would likely be many different opinions. Talks between countries on how best to pay doctors would be a "dog's breakfast," says Levinson. The Choosing Wisely concept, on the other hand, has seen few detractors.

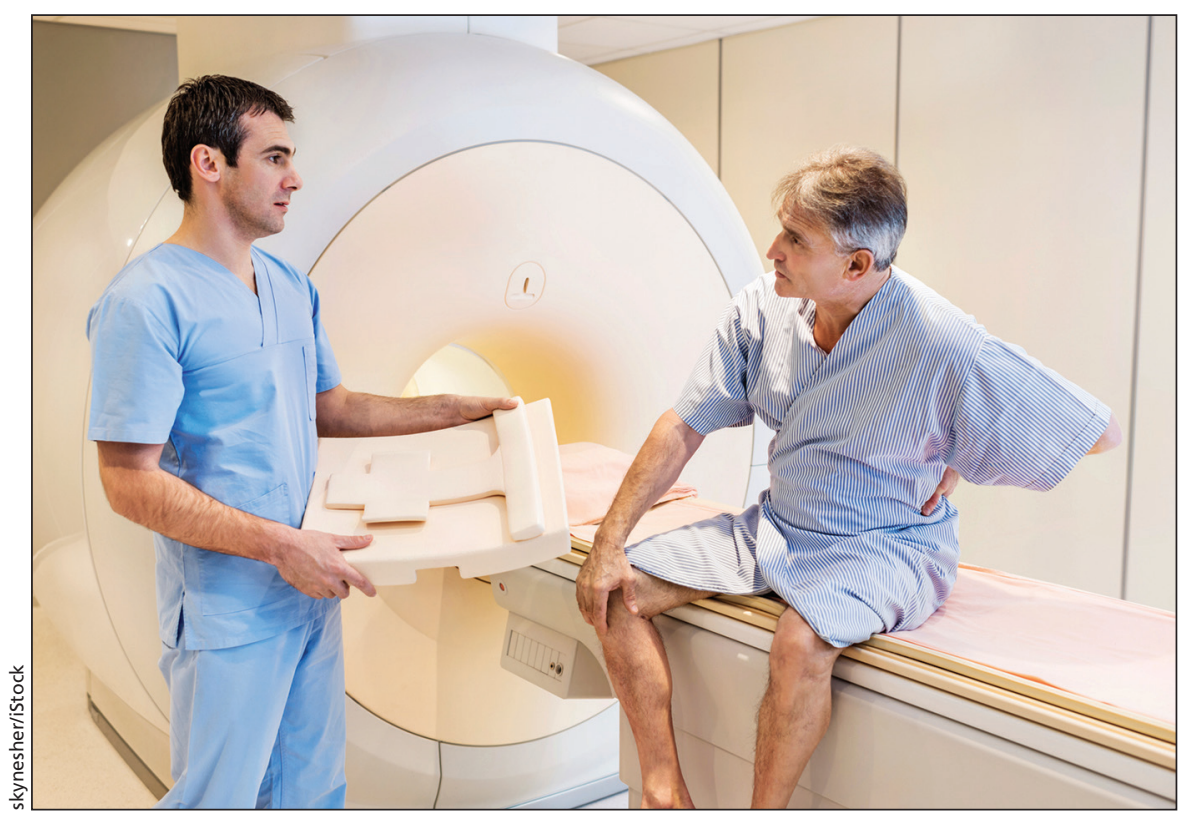

Physicians in many countries agree that reducing the use of some medical tests, such as MRI scans, is a good idea.
The success across borders of Choosing Wisely is even more amazing, says Levinson, when you consider the financial incentives for physicians - there are none. No one is getting paid to choose wisely, she says. Sure, health systems that reduce overuse may save some money, but the campaign is really about quality improvement and harm prevention, about delivering high-

\section{"It's about the day-to-day practice of medicine.... It's about helping more and harming less."}

That's because it is at the core of physician professionalism, says Levinson. It's about the day-to-day practice of medicine - working with patients to decide which tests are really necessary, which drugs they really need, how much care is enough and how much is too much. It's about helping more and harming less.

"The work of doctoring is the same in every country," says Levinson. quality, appropriate care for patients based on the best available evidence.

But even such an appealing concept - providing value in health care can only spread across the world if someone takes leadership of the initiative. In this case, that leader is Canada.

"We are kind of the consultants to the other countries," says Levinson.

It is the Canadian team that organized and ran the international consor- tiums held over the past three years in Amsterdam, London and Rome. It is the Canadian team that pushed for the Commonwealth Fund to include questions on overuse in its surveys. Choosing Wisely Canada is also responsible for overuse indicators appearing in Health at a Glance 2015 by the Organisation for Economic Co-operation and Development (OECD).

"If we hadn't articulated the importance of it to the OECD, they wouldn't have done it," says Levinson.

Canada is not only leading, but also learning from Choosing Wisely successes in other countries. Israel and Australia, for example, have shown tremendous capacity to measure the effects of Choosing Wisely initiatives, thanks to their excellent systems of electronic health records.

"We want to keep learning from each other, growing measurement and teaching the public that more is not always better," says Levinson. Roger Collier, CMAJ

CMAJ 2016. DOI:10.1503/cmaj.109-5291 